\title{
Work in Progress: Examining the Value of Reflection in Engineering Practice and Education
}

\section{Dr. Kristine R. Csavina, Colorado School of Mines}

Dr. Kristy Csavina is a Teaching Professor in the Department of Mechanical Engineering at the Colorado School of Mines. She has her bachelors degree in Mechanical Engineering from the University of Dayton and her doctorate in Bioengineering from Arizona State University.

\section{Dr. Adam R. Carberry, Arizona State University}

Dr. Adam Carberry is an assistant professor at Arizona State University in the Fulton Schools of Engineering, The Polytechnic School. He earned a B.S. in Materials Science Engineering from Alfred University, and received his M.S. and Ph.D., both from Tufts University, in Chemistry and Engineering Education respectively. Dr. Carberry was previously an employee of the Tufts' Center for Engineering Education \& Outreach and manager of the Student Teacher Outreach Mentorship Program (STOMP).

\section{Dr. Trevor Scott Harding, California Polytechnic State University, San Luis Obispo}

Dr. Trevor S. Harding is Professor of Materials Engineering at California Polytechnic State University where he teaches courses in materials design, biopolymers, and nanocomposites. Dr. Harding has served as PI of a multiinstitutional effort to develop psychological models of the ethical decision making of engineering students and measure this decision-making within the context of both pro-social and antisocial behaviors. He is heavily involved in the ERM, Materials, and Community Engagement divisions of ASEE. He received the 2008 President's Service Learning Award for innovations in the use of service learning at Cal Poly. In 2004 he was named a Templeton Research Fellow by the Center for Academic Integrity. Dr. Harding received both the 1999 Apprentice Faculty Grant and 2000 New Faculty Fellow Award for his contributions to engineering education.

\section{Dr. Patrick Cunningham, Rose-Hulman Institute of Technology}

Patrick Cunningham is an Associate Professor of Mechanical Engineering at Rose-Hulman Institute of Technology. During the 2013-14 academic year he spent a sabbatical in the Department of Engineering Education at Virginia Tech. Dr. Cunningham's educational research interests are student metacognition and self-regulation of learning and faculty development. His disciplinary training within Mechanical Engineering is in dynamic systems and control with applications to engine exhaust aftertreatment. 


\section{WIP: Examining the Value of Reflection in Engineering Practice and Education}

\section{Introduction}

Reflection has long been considered an important aspect of the educated practitioner (Dewey, 2012; Moon, 1999; Rose, 2013; Schön, 1983, Rodgers, 2002; Brookfield, 1995; Mezirow and Associates, 1990). We reflect any time we draw on prior experiences and use our interpretations to inform our choices and actions impacting the present or future. The Consortium to Promote Reflection in Engineering Education (CPREE) has recently made considerable progress in promoting reflection in higher education engineering programs (Sepp, et al. 2015; Turns, et al. 2014; Turns, et al. 2015; Harding, et al. 2015; Carberry \& Csavina, 2015; Csavina, Carberry \& Nethken, forthcoming; Summers, et al. 2016). This exploration investigates two fundamental questions of interest: (1) how do engineering practitioners, educators, and students define reflection, and (2) what aspects of reflection are valued by these individuals?

Our purpose in studying these research questions is to inform efforts to improve educational practices in engineering and to help educators grow. The following work-in-progress study leverages our involvement, experiences, and observations within CPREE to capture the value of reflection experiences through different stakeholder lenses.

\section{Theoretical Framework}

Schön (1983) categorized reflection as "reflection-on-action" or "reflection-in-action". "Reflection-on-action" is defined as looking back on an event or experience in the past in order to learn from it, while "reflection-in-action" is defined as processing and adapting a present experience in light of prior experiences. Rose (2013) adds a third category of reflection, "reflection-then-action," which includes processing prior experiences to direct future choices. Schön and Rose's definitions enumerate on the temporal aim of reflection. This study will focus on this temporal aim of reflection as it is closely tied to individual's values of reflection.

Our current work is framed by Expectancy-Value Theory (EVT) (Wigfield \& Eccles 2000, Eccles \& Wigfield 2002) focusing specifically on how individuals value their current reflection activities. Task value is influenced by utility value, attainment value, intrinsic value, and cost. Utility value refers to the perceived usefulness of the task towards achieving an individual's future plans or goals. Attainment value refers to the importance of doing well on a particular task. Intrinsic value applies to tasks individuals take pleasure in, enjoy, or find interesting. Cost refers to the negative consequences of engaging in a task.

\section{Research Methods}

Sample: Researchers from four distinctly different institutions implemented an initial assessment of faculty, students, and practitioners to investigate how each group defined reflection and what value they associated with reflective practices. Students and faculty surveyed included a wide range of engineering disciplines based on the distribution at each institution. Practitioners were identified from industrial advisory boards, capstone affiliations, alumni, and colleagues. Responses were obtained from 458 respondents - 295 students, 67 faculty, and 92 practitioners. An additional 288 partially completed responses were also collected. A randomly selected sample of 159 respondents (53 from each group) was analyzed for this exploratory study. 
Data Collection: The survey consisted of five total questions to better understand how each respondent defined reflection, used reflection in their daily, professional and/or academic lives, and how reflection was valued. Responses were collected using an online survey.

Data Analysis: This paper focuses on analyzing respondent's definitions of reflection and their associated value of reflection. An emergent set of codes for each question was determined by first having each researcher review and evaluate ten identical responses to identify common words/phrases and predominate themes. The researchers then discussed the codes during multiple iterations to ensure rater reliability. Each researcher subsequently coded approximately 40 responses individually. Difficult to code responses were discussed among the coders.

The following three primary codes emerged for definitions of reflection: 1) looking back, 2) apply to present, and 3) affect the future. These responses align with the three models presented earlier describing the relationship between action and reflection. Four primary codes emerged to classify responses regarding the value of reflection: 1) time, 2) space, 3) improvement, and 4) making meaning. These codes appeared in the literature as requirements for reflection. For example, Rose (2013) argues that reflection requires deliberate quiet time and space to truly allow one the opportunity to reflect. Additionally, CPREE has recognized that one component of reflection is, "...exploring the meaning of experiences" (CPREE, 2016). Examples of coded responses for both the definition of reflection and the value toward reflection are listed in Table 1. It is important to note that some responses were coded using multiple codes (see Results section for details).

Table 1: Codebook used with example responses.

\begin{tabular}{|c|c|}
\hline Codes & Example Responses \\
\hline \multicolumn{2}{|l|}{ Defining Reflection } \\
\hline $\begin{array}{l}\text { Looking Back } \\
\quad \text { (LB) }\end{array}$ & $\begin{array}{l}\text { "Reflection is a mental review of the past in search of what went right, what went wrong, } \\
\text { and how things could have been better or even worse." }\end{array}$ \\
\hline $\begin{array}{l}\text { Apply to Present } \\
\text { (AP) }\end{array}$ & $\begin{array}{l}\text { "Time to pause and think deeply about what is going on, also time to clear one's mind to } \\
\text { think more clearly." }\end{array}$ \\
\hline $\begin{array}{l}\text { Affect the Future } \\
\text { (F) }\end{array}$ & $\begin{array}{l}\text { "A moment in time when you stop and look back on where you have been, what you have } \\
\text { learned, and how this will impact the future." * }\end{array}$ \\
\hline \multicolumn{2}{|c|}{ Value toward Reflection } \\
\hline Time (T) & $\begin{array}{l}\text { "Getting the actual time to slow down and think, with no other expectations on how I'm } \\
\text { spending that time." }\end{array}$ \\
\hline Space (S) & "Peace of mind, the ability to project one's thoughts" \\
\hline Improvements (I) & "Reflection improves performance, and thus satisfaction, with time." \\
\hline $\begin{array}{l}\text { Making Meaning } \\
\qquad(\mathrm{MM})\end{array}$ & $\begin{array}{l}\text { "Opening your mind' to allow new perspectives/insights to surface which wouldn't be } \\
\text { possible without the reflection." }\end{array}$ \\
\hline
\end{tabular}

* Note: response was coded as both looking back and affect the future. 


\section{Results}

Defining Reflection: All definitions of reflection were coded using one ( $55 \%)$, two ( 37\%), or three $(\sim 8 \%)$ codes per response. Twenty-two of the responses provided new information when offered the opportunity to add or modify their original definition for reflection. Codes from responses that included additional information or a modified definition at the end of the survey were summed. The majority of responses keyed in on reflection as a way to look back on a past experience or event $(\sim 65 \%)$. Almost half of the sample $(\sim 48 \%)$ described reflection as applying to the present, while just under a third $(\sim 33 \%)$ cited reflection as impacting future actions. Few responses provided scientific definitions of reflection $(\sim 6 \%)$. Practitioner responses fell approximately right on the mean for all four categories. Faculty were observed to cite looking back and a scientific definition at a greater rate and applying to the present at a lower rate. Students displayed the exact opposite trend. Both groups were approximately around the mean for considering the future. An ANOVA analysis across the three groups revealed no significant difference between groups for any of the four codes.

Value toward Reflection: All responses regarding associated value toward reflection were coded using one $(\sim 87 \%)$, two $(11 \%)$, or three $(2 \%)$ codes per response. The majority of responses valued reflection as a way to improve $(\sim 57 \%)$. Far fewer responses were coded as making meaning $(\sim 28 \%)$, time $(\sim 15 \%)$, or space $(\sim 6 \%)$. Approximately $9 \%$ of the responses were not coded due to confusion by the respondent or an inability by the researchers to fit the response within the established coding scheme. Responses across groups were remarkably similar with students demonstrating a higher rate of responses coded as space $(\sim 11 \%)$ and improvement $(\sim 62 \%$.) An ANOVA analysis across the three groups revealed no significant difference between groups for any of the codes.

Correlations between Defining Reflection and Value toward Reflection: Correlational analysis was conducted to identify significant correlations between how respondents defined and valued reflection. Two significantly positive correlations were observed with those who valued reflection as an opportunity to improve. These correlations existed with the 'looking back' code $(r=0.200 ; p \leq 0.05)$ and 'affect the future' code $(r=0.247 ; p \leq 0.01)$. Both correlations were positive, meaning those valuing reflection as an opportunity to improve were more likely to provide a definition that focused on looking back and/or affecting the future.

\section{Discussion}

Our starting point for this research was a desire to understand the ways in which educators, students, and practitioners define and value reflective practices. Perhaps the most interesting finding is that respondents to our qualitative, open-ended survey overwhelmingly responded with positive perspectives on reflection; negative comments are absent from our data as evidenced by the lack of a cost-related code pertaining to value toward reflection. Clearly this may be a result of selection bias, but it is heartening to know that there are a significant number of students, faculty, and practitioners that value reflective practices for a variety of different reasons.

We found that respondents most commonly reported definitions coded as looking back on past experiences. It is not surprising that many respondents would see reflection as something you do after an event. A slightly smaller number of respondents reported applying reflective thinking to the present. This would seem to be a more nuanced understanding of reflection and one that is less often considered. Schön (1983) considered reflection-in-action as most critical to the 
professions because it enables professionals to manage ambiguity, uncertainty, and complexity in the moment. The smallest subset of respondents reported applying reflective thinking to improve future outcomes. The fact that so few respondents considered "reflection-then-action" in their definitions is somewhat surprising given that one would expect individuals to see utility in reflecting on the past to improve the future. This is an interesting finding, but we acknowledge that in their desire to complete a survey quickly, the respondents may simply not have given their full consideration to the definition of reflection.

We observed little difference in the definitions of reflection provided by the three groups. Faculty were slightly more likely to define reflection as an action occurring in unison with a task compared to students and practitioners. This result was not statistically significant, but the difference would suggest that faculty are potentially more likely to reflect in the moment of activity compared to practitioners and students.

Our examination of respondent's values toward reflection revealed that they most commonly valued the opportunity that reflection afforded for improvement. Improvement, as a code, included many sub-codes based on the context of the improvement. Most responses focused on self-improvement, including making future events generally better or parsing out areas of an individual's life in which they envisioned self-improvement. Self-improvement was seen to represent either utility or attainment value.

Making meaning of past experiences was coded most frequently after improvement. We found that responses coded as making meaning were typically focusing on developing skills. We imagine that making meaning best aligns with either utility value or intrinsic value. This assertion is a bit more speculative, but we believe most respondents coded for making meaning referred to developing new ways of thinking about issues and developing a "toolbox" of new perspectives. We hypothesize that individuals see having new perspectives as either useful in solving future problems (utility value) or personally enjoyable (intrinsic value). More refined coding may be needed to parse these differences out.

The least often used codes were time and space. Respondents referred to finding pleasure and personal fulfillment in the time and space afforded by reflecting - aside from any utility it may provide. Time and space are clear examples of intrinsic value because respondents repeatedly referred to the simple pleasure of having time and space to reflect without referring to any particular outcome associated with the reflection.

\section{Limitations}

We recognize that there are a number of possible limitations to this exploratory study. First, we used a sample of convenience for this pilot study, recruiting students, faculty and practitioners from our home institutions and our personal contacts where possible. This clearly does not represent a random sampling of these populations. Second, we are unable to precisely calculate the response rate to our survey. Many inquiries were made to obtain a sample that included students, faculty, and practitioners. Those who did respond may have been more inclined to respond to the survey because they currently use and value reflection. This in turn may have biased our results on the value of reflection by producing predominantly positive responses to this part of the survey. We do believe that there are those who likely view reflection as too much effort or time. Third, for this study we report data from only a subset of our total data set in order 
to have equal distribution of the three groups for analysis. We may have inadvertently selected a non-representative set of responses from our sample through our random selection process.

Finally, the questions asked were designed to be direct and brief. We believe this led to a higher than expected response rate from our sample of convenience, but the nature of the questions may not have led to rich responses from respondents. This potentially limited our ability to accurately code some responses.

\section{Future Work}

We envision the results of this research being paired with the initial work of CPREE to further advance our understanding and use of reflection in engineering education. The emerging findings provide us with a better understanding of the ways in which different engineers and engineering learners define and utilize reflection. This, and subsequent efforts, will help to illuminate barriers to overt reflective practice and mechanisms for developing productive reflective practice. What emerges from these studies will provide a foundation for our future work investigating change efforts at our institutions that aim to positively impact faculty and engineering students' value of reflection as a professional engineering skill and their associated reflective practice within teaching, learning, and engineering work.

\section{Acknowledgement}

This material is based on work supported by The Leona M. and Harry B. Helmsley Charitable Trust through funding of the Consortium to Promote Reflection in Engineering Education (CPREE), a collaboration of twelve educational institutions http://cpree.uw.edu.

\section{References}

Borrego, M. \& Henderson, C. (2014). Increasing the Use of Evidence-Based Teaching in STEM Higher Education: A Comparison of Eight Change Strategies. Journal of Engineering Education, 103(2), 220-252.

Brookfield, S. (1995). Becoming a Critically Reflective Teacher. San Francisco: Jossey-Bass.

Carberry, A. \& Csavina, K. (2015). Assessing Student Understanding of Reflection in Engineering Education. American Society for Engineering Education Annual Conference \& Exposition.

CPREE (2016). (n.d.). Retrieved February 10, 2017, from http://cpree.uw.edu/what-is-reflection/

Csavina, K., Carberry, A., \& Nethken, C. (forthcoming). Understanding perceptions of reflection among engineering educators and students. International Journal of Engineering Education.

Dewey, J. (2012, reprint of 1910 original). How We Think. San Bernardino, CA: Renaissance Classics.

Eccles, J. S. and Wigfield, A. (2002). Motivational beliefs, values, and goals. Annual Review of Psychology, 53, pp. 109-32.

Harding, T., Chen, K., Vanasupa, L., Domingo, L., Colvin, K., Pande, A., Kawahara, T., Slivovsky, L., Peuker, S., Widman, J., Schuster, P. (2015). The Role of Collaborative Inquiry in Transforming Faculty Perspectives on Use of Reflection in Engineering Education. Frontiers In Education Annual Conference.

Mezirow, J.A. \& Associates (1990). Fostering Critical Reflection in Adulthood. San Francisco: Jossey-Bass.

Moon, J.A. (1999). Reflection in Learning \& Professional Development: Theory and practice. London: RoutledgeFalmer.

Rodgers, C. (2002). Defining Reflection: Another Look at John Dewey and Reflective Thinking. 
The Teachers College Record, 104(4), 842-866.

Rose, E. (2013). On Reflection: An essay on technology, education, and the status of thought in the Twenty-first century. Toronto: Canadian Scholar's Press Inc.

Schön, D. A. (1983). The reflective practitioner: How professionals think in action (Vol. 5126). Basic books.

Sepp, L.A., Orand, M., Turns, J.A., Thomas, L.D., Sattler, and Atman, C.J. (2015). On an upward trend: Reflection in engineering education. American Society for Engineering Education Annual Conference \& Exposition.

Summers, S, Chenette, H., Ingram, E., McCormack, J., and Cunningham, P. (2016). CrossDisciplinary Exploration and Application of Reflection as a High Impact Pedagogy. Insight: A Journal of Scholarly Teaching, v11, pp. 29-47.

Turns, J.A., Sattler, B., Thomas, L.D., Atman, C.J., Bankhead, R.B., Carberry, A.R., Csavina, K.R., Cunningham, P.J., Faust, D.K., Harding, T.S., Yasuhara, K. (2015). Reflecting on reflection. How educators experience the opportunity to talk about supporting student reflection. American Society for Engineering Education Annual Conference \& Exposition.

Turns, J.A., Sattler, B., Yasuhara, K., Borgford-Parnell, J.L. and Atman, C.J. (2014). Integrating reflection into engineering education. American Society for Engineering Education Annual Conference \& Exposition.

Wigfield, A. and Eccles, J. S. (2000). Expectancy-value theory of motivation. Contemporary Educational Psychology, 25, pp. 68-81. 